\title{
keepgrabbing.py : final additions, more documents
}

\author{
Camille Akmut \\ January 14, 2020
}

\begin{abstract}
Further notes and documents around this program. Including "Aaron Swartz and the social sciences" - a bibliography.
\end{abstract}


Additions (2)

- Further antecedents : Swartz as a freshman at Stanford in 2004

“They register your computer's MAC address so they can track you if you take your laptop anywhere. (...) [The ID card] has a RFID transmitter in it, so they can track us while we walk."

(Swartz, 2004, "Stanford” series of blog post, the old blog (called 'The Weblog'?))

(l'm pretty sure this is something that was overlooked by Abelson et al., as well.)

RFID : Radio-frequency identification. "An RFID tag consists of a tiny radio transponder; a radio receiver and transmitter." (Wikipedia)

- Hand calculation

l'll go through the whole calculation (and end program output) once more, by going through a fictive example :

Say, "regions_and_social_groups" was one of the outputs from getblocks()*, then this is what the lambda function would do with it :

(*an actual title of a paper by Bloch)

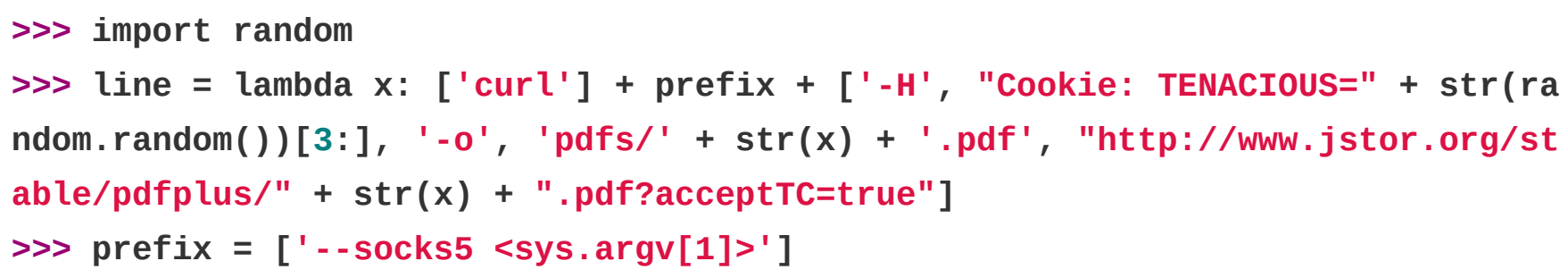

Result, application :

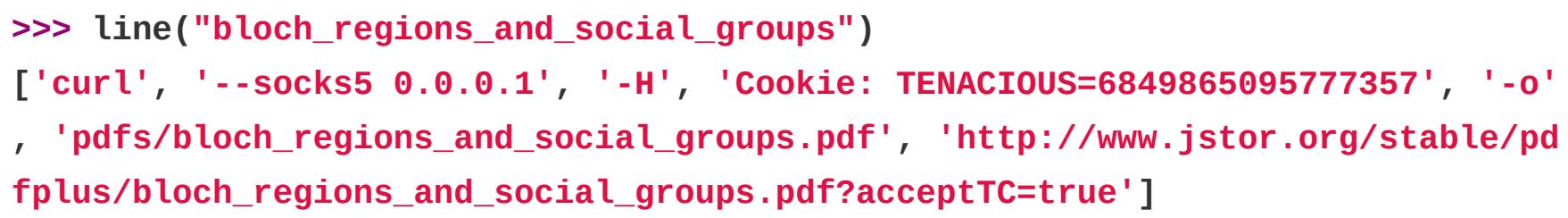


(I've cheated with prefix : sys.argv[1], as its naming convention implies, is an argument taken from the command line e.g. 0.0.0.1,

but for demonstration purposes will do.)

If this was an Arxiv-style database, with numbered nomenclature, e.g. 5051.pdf, we'd have :

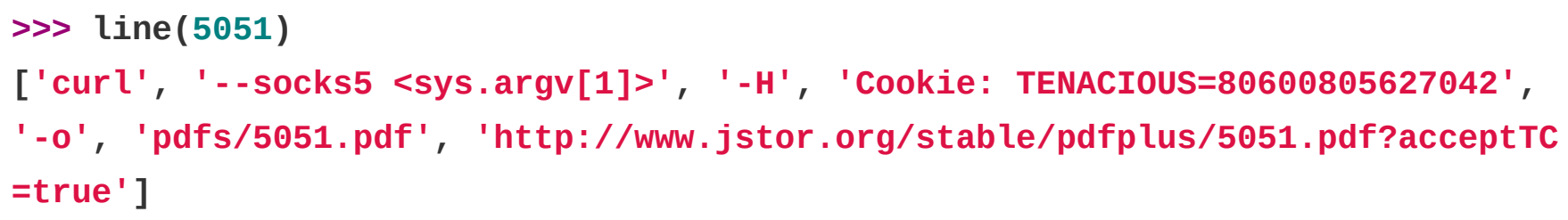

instead.

(Notice how the cookie value changes with every execution.) 
Annex

- Document 1 : Swartz, Aaron. 2004. "Stanford: Day 4".

- Document 2 : "Aaron Swartz and the social sciences" (a bibliography) 


\section{Stanford: Day 4}

This week we were repeatedly informed about the "unprecedented personal freedom" that we would have at Stanford. Apologies, but I don't see it. First, I stay in a three-room system with four other people (two two-person bedrooms on either side and a shared office in the middle). Our only bathroom is down the hall, where there are five stalls shared with the whole hall. This means practically everything I do - sleeping, waking up, alarm clocks, working, showering, etc. must be coordinated so as not to interfere with those other people. Stupid other people...

Of course, this is not an accident. The whole thing is a giant privately-owned community, like some sort of Disney World. The run the government, the police, the restaurants, the bookstores, the shopping center, the transportation, the entertainment, etc. Worse yet, they track you while you use it all. Everyone gets an ID card which must be swiped to eat, visit the library, use a computer terminal, check your mail. It even has a RFID transmitter in it, so they can track us while we walk. (They didn't bother to tell us this and we wouldn't notice because it looks just like a regular card. I just found out because I happened to walk by a reader.) They register your computer's MAC address so they can track you if you take your laptop anywhere.

It's like I've woken up in some sort of libertarian nightmare world, where one company has bought up everything and now tells everyone what to do. Obviously there's no freedom, but the ardent libertarians still say "Look at how free you are! There's no government telling you what to do!" If this is freedom, I think I might prefer tyranny.

All this by way of saying, I get to take a shower for the first time today. Honestly, with all the money they seem to have around here, it wouldn't kill them to just build a few hotels. But I guess removing self-dignity and privacy is part of building conformity and obedience. I don't know the history, but I might venture to guess they borrowed the whole thing from the military.

After my shower, I head over for breakfast, but apparently the cafeteria decided to close half an hour early. I run all over campus looking for a bagel. Eventually, I am about to go to the library to try Googling for a bagel, but I am spared from this indignity by a bagel shop just outside the library.

$$
* * *
$$

When I'm back at the cafeteria for lunch, I notice a bizarre note placed at each table. It's a letter from the head of Stanford Dining, praising their great work: 
“extremely excited...cuisine experiences...enthusiastically prepare...passionately serving...36 years...chefs trained at world-renowned schools... recruited from top industry performers...nationally recognized, award winning". I try and think about the process that put this bizarre note here. Who are they trying to impress? Certainly not the students, who are required to buy the food and, in any event, are going to end up eating it, propaganda or not. (I can tell you, it doesn't taste award-winningly good.) The whole thing is bizarre.

$$
* * *
$$

Today's afternoon event is "Faces", a collection of student speeches and arts performers meant to highlight diversity at Stanford. The upperclassman who leads our hall insists we all dress weirdly for the event. I get to wear a wig. As the leader note, the end effect is to make all the boys look gay (or, in one case where breasts were worn, lesbian). When we get to the auditorium and mix with the other kids, it's hard to tell who's dressing weird and who just dresses like that.

Inside, it's a beautiful, touching show, that would likely make even the most staunch opponent of equality reconsider, but it contains puzzles nonetheless. One boy tells us he had bipolar disorder - he pushed himself too hard, failed miserably, and was put on academic probation and is suspended for a year. Sent home to sit and be depressed alone, things just get worse for him. He eventually comes back and manages to make a recovery when the stakes are high (if he screws up again, he gets suspended for three years!) and begins to take on more work and succeed. It's a touching story, but there's some sort of a breakdown somewhere.

Why did Stanford torture this poor, sick boy, doing his best to succeed? What sense does it make to suspend him because he tried too hard? Where was the care for this poster boy of the diversity they claim to champion? How can they expect anyone to push themselves if they threaten to suspend them for years if they fail? It makes no sense.

Afterwards, we break into small groups for discussion. Ours ends up becoming a debate about affirmative action. (Perhaps partially my fault, because I remember what I read in The Language War and suggest that the event had the implict message that "We, the straight upper middle class white people, are the normal ones".) Stanford has "theme houses" for blacks, hispanics, etc. Anyone can apply and apparently they try to make it half racial group, half others, but apparently it's still controvertial here. Isn't just another form of segregation? one Asian girl asks.

I respond that Stanford is comically segregated. Our dorms are segregated by what classes we're taking, our peer advisor groups are segregated by engineering/humanities, why, we even have separate libraries for engineering 
students. Why, I ask, are we arguing about the one form of segregation that might actually be beneficial? The answer, of course, is because we're still so selfconscious about race.

See, the thing about race is that while it's usually a liberal/conservative issue, it's not a corporate one. Corporations don't care if their employees or managers are white or black, as long as they act the same as the other managers. Indeed, corporations probably benefit from increasing the size of the workforce. So if you get the liberals distracted by arguing about race, maybe they'll ignore the more important dehumanizing and corporatizing part of all this.

Later that night, The Sexual Health Peer Resource Center (SHPRC) puts on a seminar about sex at Stanford. For unclear reasons, sex is still a tabo topic in America, even among these jaded, elite, attractive teenagers. (Even at our supposedly-hardbitten "The Real World" play, they euphemized about "other things on the menu".) The SHPRC tries valiantly to overcome this. As I walk in, they're rattling off statistics about how frequently each set of body parts is combined. They give us cards so we can ask questions anonymously and use laughter as a way of loosening things up (how in the original version, The Prince rapes Sleeping Beauty and leaves before she wakes up, how lesbians sometimes exclude bi people because they're sleeping with The Man, etc.). They also have an impressive set of portmanteau words - you sexile (sex + exile) your roommate, avoid dormcest (dorm + incest), etc. They also tell us about all the free stuff for students: free condoms and lube, free STD testing, free advice, free classes, etc. It was a valiant effort.

$$
\text { * * * }
$$

When I'm back in my dorm, no sooner does the Internet come back up (a router had apparently blown up) than a bunch of kids, dressed in naked clothes and bikinis, start running through the halls singsonging "let's go Roble [clap, clap, clap clap clap] fountain-hopping [clap, clap, clap clap clap]". I quickly realize that fountain-hopping does not mean travelling to visit the campus's beautiful fountains, but instead running around campus and jumping into them. I decide to follow and take notes.

We run through the streets (there are no supervising police this time, apparently the thing was one girl's spontaneous idea that just sort of snowballed) to the nearest fountain, where everyone jumps in and starts splashing each other. There appears to be something of a code of conduct - there is no actual nudity and the group eschews puny sprinklers. Apparently l've picked a good one. One kid comments this is "the most fun fountain hopping I've ever had" and suggests we do it every thursday night. 
The singsonging seems to be some sort of consensus process, when people are all spread out in the fountain it suddenly switches to "everyone together [clap, clap, clap clap clap]" as people move together in the center. One guy carrying a boombox puts on "Baby Got Back", which seems to be a popular cross-gender choice. The group sings along, even spontaneously splitting up the group in half to take the different parts. The cooperation is incredible.

Later I learn things always weren't so good, when one girl notes that they're "trying to say away from tearing curtains down, banging doors down" this year.

Closing out this busy night is a show from the Stanford Improv Society or SImps. Even though they're performing in a different theater at a different time from our usual meetings, and the crowds are thoroughly mixed, unlike our usual seating by dorm, interdorm cheering still erupts. (Kids across the audience stand up to cheer for their dorm.) I briefly imagine what things would be dorms were numbered, like MIT's buildings:

What's the dorm with the perfect num?

E forty-nine minus twenty-one!

That wouldn't be so bad, I guess.

Improv is one of the most cooperative of games - it's all give and take between partners, working together to make something funny. It's really a lot of fun. (Studies with small children have shown competitive games are less enjoyable, less effective, and more demotivating than cooperative games.) But here, even improv is made competitive - people are split into two teams and forced to compete for our applause. They do an applause poll after every two acts; not surprisingly, the team who went second wins every time.

posted September 24, 2004 02:49 PM (Education) (19 comments) \#

\section{Nearby}

«prev | $\underline{\text { up }} \mid \underline{\text { next } »}$

Published Author

Stanford: Day 1

Stanford: Day 2

Stanford: Night 2

Stanford: Day 3

\section{Stanford: Day 4}

Stanford: Day 5 
[REDACTED] Update

Stanford: Day 8

Stanford: Day 9

Stanford: Day 10

Aaron Swartz (me@aaronsw.com) 


\section{BIBLIOGRAPHY : AARON SWARTZ AND THE SOCIAL SCIENCES}

Swartz, Aaron (Lucchese ed.). 2014. Raw Thought, Raw Nerve. Inside the Mind of Aaron Swartz.

- What is going on here? (2006)

"In his 1959 classic, The Sociological Imagination, the great sociologist Charles Wright Mills told students of the discipline..."

- Stanford: Psychology is a Fraud (2005)

"Instead of dropping the theory, they decided to just ignore the experiments..."

- Freakonomics (2005)

"I happen to be taking a class on sociological methods. The other day we had a section where the TA showed us how to use SPSS (...)

Sociologists write many amazingly well-written and fascinating books, (...) yet none of them have seen anything like the publicity this book has.

I don't think it's a coincidence that it took an economist to write a sociology book before it could be given publicity. Sociology raises too many problematic questions about society but an economist can do somewhat interesting things while continuing to endorse the status quo."

- The Hard Sciences (2006)

"The reason is, because the "soft" sciences are, in fact, harder."

Compare with Paul Graham's prose on this subject (opposite, largely ignorant outlook).

Compare also with Bourdieu et al.'s 1968 Le metier de sociologue [The Sociologist's Craft], where similar arguments were developed : e.g. atoms don't talk back, but people do - making the "job" of the sociologist significantly harder. (I don't think this has been translated yet, either. A collection of epistemological writings by various philosophers-historians of science with their commentary.)

- The Book That Changed My Life (2006)

one night, I watched the film Manufacturing Consent: Noam Chomsky and the Media (...) [then] read Understanding Power, a thick paperback I picked up at the library. Edited by Peter Mitchell and John Schoeffel, two public defenders in New York (...) One terrifying side effect of learning the world isn't the way you think is that it leaves you all alone. 